\title{
Volatility and Spillovers With Special Reference to the NSE (National Stock Exchange) Indices
}

\author{
Trinley Paldon \\ Xavier Institute of Management \& Entrepreneurship (XIME)
}

\begin{abstract}
The characteristics of understanding the asset's behavior is examined in terms of influence of its past information or shock on its return behavior on the different broad market indices from NSE (National Stock Exchange). The GARCH family models were used to find best model fit based on the Akaike Info Criteria and Schwarz Info Criteria. From the empirical results, it is found that all the characteristics in regard to the spillover, persistence of volatility and leverage effect are persuading the variance on the selected index spot return during the selected sample periods.
\end{abstract}

Keywords: EGARCH, GARCH, TGARCH

\section{INTRODUCTION}

"You pay a very high price for a cheery consensus. It won't be the economy that will do in investors; it will be the investors themselves. Uncertainty is the friend of the buyer of longterm values".

Warren Buffett

Volatility is the uncertainty and the core of financial estimates study and that the underlying asset by its nature will revert to its mean which is not constant and time varying (Guo, Weiyu, and Wohar, 2006; Engle and Patton, 2001; Shenbagaraman, 2003). To the investors or economic agents, the answers to these following questions are pertinent in understanding when the volatility will last or what kind of volatility is prevailing at the moment; are the trends projecting clustering volatility or does the variance have spillover effect or does the shock have influence over the future volatility on the asset's return or prices? The curiosity regarding how informational transition is affecting the particular index return and its variance has become part of this study on the high frequency time series data analysis. The typical Capital Asset Pricing theory states that risk or variance comes along with a return and one would benefit if the volatility prevailing in the underlying asset (Bollerslev and Mikkelsen, 1999) is taken advantage of through proper analysis and action.

The variance in the return of the asset may be affected due to endogenous or exogenous variables. This current work is chosen to focus on the variable's past error term as the past residuals can also affect the present asset behavior instead from an exogenous variable (Ghulam, 2013). Therefore, an accurate and appropriate volatility estimate is useful in determining the prices of the underlying asset(Lee, Jiang and Indro, 2002). Volatility in the underlying asset prices can be studied by analyzing the Market Volatility Index (VIX) (Khanra and Dhir, 2017; Copeland and Copeland, 1999; Goldwhite, 2009; Barinov, 2012). It 
is implied historical volatility of the market that is forward-looking and constantly updated. The past work of authors claimed superiority of using VIX stating it can suggest mean reversion on weekly changes which all the time series data can by undertaking a longer sample period. The ideation of establishing VIX was a noble one and a new measure (Fleming and Whaley, 1995). It was a big step in understanding the market volatility (Copeland and Copeland, 1999). Khanra and Dhir (2017) examined volatility in the stock prices by using VIX on the individual stock capitalization from NSE (National Stock Exchange). Their study was found having limitations in understanding the stock indices volatility due to comparing the overall stock index volatility (VIX) to each individual index (Largecap, Midcap and Smallcap) in India as the percentage contribution to the total market index from NSE Smallcap is 2 percentages, NSE Midcap is 12.9 percentages while NSE Largecap is contributing 76.8 percentages as per the latest report from NSE (National Stock Exchange, 2020). In addition to that, the work of Angelidis and Tessaromatic (2005) also supports the importance of studying each market capitalization rather than considering the overall market risk to ascertain each market capitalization risk or volatility.

Therefore, the contributions of this work on estimating the individual stock index volatility behaviors are numerous. First, Eun and Lai (2008) has taken all the three total value of market capitalization but their study objective was to find the potential of Smallcap for building international portfolio diversification whereas all the individual stock index is considered in this study to understand the variance in the index returns, informational transfusion and its own past shock affecting the current return volatility. Second, Koulakiotis, et al., (2015) studied all the variables by using only the EGARCH model without testing for the best model fit under the GARCH family model therefore the researcher felt their study can be wholesome if proper analysis was rigorously examined which is considered in this study on each individual stock return. Third, Liston and Huerta (2012) has taken the three market value of capitalization, yet they have employed VIX(overall stock market volatility) and stock return index hence their work also suffers the same limitation as Khanra and Dhir (2017) study. The researcher therefore could not find one proper documented literature on estimating risks through analyzing persistence of stock return volatility, information transfusion or spillover effect, and its own past shock affecting the current spot return of Largecap, Midcap and Smallcap from NSE, India. Giliberto (2003) stated that assessing risk is necessary to design portfolios by using quantitative methods.

From the Univariate study of the series chosen for this study in the whole sample data that is from 2007 to 2019 (financial year), it is found that there is an existence and persistence of volatility on all the indices through an informational transition in time-varying phases as and when there are changes in the news especially bad news (good news) having larger (smaller) and spillover effect from the magnitude of a shock. Additionally, it is also found that its own previous day's index return is influencing its current index returns. Huberman and Regev (2001) and Andrei and Hasler (2014) stated that prices are reacting to the new information when investors are paying attention to it. Hence, the researcher felt the need for empirical research to show evidence on the underlying statistical behavior of the different total market value of capitalization through a rigorous testing. Marcucci (2005) suggested GARCH models to understand the realized volatility as it imbibes added asymmetries, long memory, or structural breaks and also volatility clustering. Therefore, the author has analyzed the information content of implied volatilities on the stock indices by employing the GARCH family models.

\section{Backgrounds of the Variables Used}

NSE (National Stock Exchange) is known for its broad market indices representing the listed company's weighted average free float market capitalization and is used for benchmark while trading. It is one of the two main indices most widely referred in India and is known for ensuring reliable and transparent systems of providing trading services and follow-on offerings to name a few.

\section{The Chosen Variables Under Study From the NSE Are Three Broad Market Indexes}

Largecap Nifty 100: It represents the top 100 companies consisting the top Nifty 50 and Nifty Next 50 listed under the NSE. It is computed using free float market capitalization method and represents about 76.8 
percent of the free float market capitalization of the stocks listed on NSE with more than Rs. 20,000 crores market value and viewed as a Largecap company.

Nifty Midcap 150: It represents the next 150 companies ranked (101-250) based on free float market capitalization and contributes 12.9 percent of the stocks listed on the NSE. The companies listed under this category are known as Midcap Company with a market value of more than Rs. 5000, but less than Rs. 20,000 crores.

Nifty Smallcap 50: It shows the benchmark of the Smallcap companies based on the free float market capitalization of below Rs. 5000 crores and also it is the top 50 companies from the Nifty Smallcap 250 listed companies. It represents about 2 percent of the free float market capitalization of the stocks listed on the NSE.

Nifty VIX: The Nifty Volatility Index measures the expected or perceived market volatility over the following 30 calendar days based on the bid-ask from the Nifty Index Option prices. It is often known as the "fear gauge". NSE started computing Nifty VIX from the year 2009 onwards.

The format of the paper is as the following, Section II presents the review of literature which is followed by Section III that highlights the methodology chosen for this study. Section IV gives detail on the data analysis conducted on the series. Section V will provide the conclusion followed by Section VI which comprises recommendations of the study. Section VII gives a direction for the future scope of study.

\section{REVIEW OF LITERATURE}

The existing literature on the stock price volatility and the various test applied to find volatility in the stock indices includes the following work; Koulakiotis, et al., (2015) have used augmented Univariate EGARCH model to estimate the impact of the effect of information on the Largecap, Midcap and Smallcap stocks. The study period is divided into two periods; 2001 to 2008 as before and 2009 to 2012 for postperiod study. They found that in both the regimes, trading volume affected in an adverse direction. Beaupain, Giot and Petitjean (2010) studied all the market indices of NYSE stocks and applied MarkovSwitching and 'market model' for the sample period 1995 to 1990 . They found volatility affects liquidity co-movements on Smallcap differently comparing to Midcap and Largecap. They concluded that the level of the co-movement is related to the market capitalization of the index and that it is less intense in the Smallcap compared to the Largecap. Similarly, Theobald and Yallup (2005)study on intraday volatility and its speeds of adjustment for U.K. stock market indices by applying GARCH and ARMA are found. Opening trade total volatility is suggested having higher than at the closing for Largecap stocks due to overreaction and depicts overconfidence bias. Whereas Midcap stocks are found showing under reactions and concluded that differential intraday volatilities on Largecap and Midcap index level are related to differential speeds of information adjustment. A study by Eun, et al. (2008)was found on 10 developed and open capital markets on risk-return behavior having considered the Largecap, Midcap and Smallcap. It was found having a correlation between Smallcap and Largecap and additionally Largecap is found to have high correlations with each other reflecting exposures to the global factors. Floros (2007) analyzed the impact of stock market volatility on Greek stock indices (Largecap, Midcap and Smallcap) by using GARCH specifications; GARCH, GJR, and EGARCH. The result showed good news having less impact in addition to the persistence of market efficiency. Angelidis and Tessaromatic (2005) studied London Stock Exchange by undertaking Smallcap and Largecap stocks along with value and growth stocks. They applied regression analysis and correlation. They found evidence that Small stocks can predict the Smallcap premium and have no relation to the market risk or value or growth spread and also it is not related to the business cycle or other liquid variables. Whereas only the Largecap stock volatility is similar to the market volatility based on a correlation test resulting in close to 1 . Shenbagaraman (2003) study on the stock volatility of Nifty futures and options was analyzed using $\mathrm{GARCH}, \mathrm{EGARCH}$, and TARCH models. They found having no significant impact on spot market volatility through derivative, yet there is evidence of change in the sensitivity of NIFTY to the S\&P 500 returns through futures. It was found that the effect of information was persistent over time in the pre-future period introduction which has disappeared in the post-introduction period. Goldwhite (2009) applied VIX to measure the volatility for the S\&P 500 by employing correlations 
analysis. They found that risk premium underperforms when risk aversion rises due to threat from economic instability and high corporate weakness. Ankrim and Ding (2002) examined the correspondence of crosssectional volatility to the active manager's distribution or response for the various equity markets. They found that the active responses are not unique to the U.S. Largecap and Small caps but also in the Canadian, Japanese, and U.K. stock. Reyes (2001) studied the Tokyo Stock exchange by using bivariate EGARCH to examine Largecap and Smallcap volatility from January 1970 to March 1996.It was found having asymmetric volatility spillover from Largecap to Smallcap returns and not vice-versa. Mele(2007) can be found examining on the consistency between countercyclical stock market volatility and rational asset evaluation through the price-dividend ratio. The variables are the S\&P composite index, 1-month T-bill by applying standard deviation. It was found that there are no implications of countercyclical risk premium to countercyclical return volatility as it was occurring only when risk premium increases during bad times and decreases in good times, resulting in fluctuations of price-dividend ratios more in bad times and vice-versa. Zundert (2017) tried to project volatility in the constructions of the portfolio by applying the Sharpe ratio and compared between equal-weighted momentum, value-weighted momentum and volatility-adjusted momentum on Largecap and Smallcap. It was found that value-weighted momentum resulted in a much higher Sharpe ratio in comparison to equal-weighted momentum based on higher returns in the valueweighted portfolios. Smallcap is found to be underperforming due to the equal-weighted versus marketweighted.Kuo and $\mathrm{Li}$ (2013) studied both the developed and emerging capital markets and concluded based on Sharpe ratios that investors have become cautious and avoids unnecessary risk. Ozenbas, et al., (2010)studied Largecap, Midcap and Smallcap from Nasdaq, NYSE and FTSE by applying Market model, cross-sectional relative-return and intraday volatility. It was found having the worst market quality during the opening for Largecap comparing to Midcap and Smallcap and the relative trading in volume is higher for Largecap, yet it does not differ during closing volatility among the indices. Onyeaso and Rogers (2004) examined the volatility of 600 Smallcap by applying GARCH and TARCH. It was found that volatility in the 600 Smallcap indices can be predicted like other stocks and depicts market efficiency. Conrad and Weber (2013) analyzed volatility spillovers by using multivariate GARCH family models. They found that small firm shocks affect the large firm conditional variance when negative spillovers are allowed between the conditional variances.(Bolllerslev, Tim and Mikkelsen, 1996). Hiremath and Kamaiah (2010) examined the long memory in volatility on the Indian stock market; National Stock Exchange (NSE) and Bombay Stock Exchange (BSE) by employing Fractionally integrated generalizes autoregressive conditional heteroscedasticity test. They found having existence of long memory in volatility on all the index returns. Lizhong and Meng (2013) study on the existence of feedback trading behavior on the Chinese open-ended funds' transaction and its impact on stock price volatility is found. They reported that Smallcap volatility was caused by fund momentum trading behavior whereas the fund reverse transaction behavior caused more Largecap stock volatility. Wei and Yang (2011) analyzed the leverage effect caused by the Taiwanese government's trading restrictions by using EGARCH model. They found association of high liquidity with Large stocks increasing asymmetric volatility but it is not so for the Middle and Small stocks as both decreased during naked short sale ban. Marcucci(2005) tried to project U.S. stock market volatility by using GARCH family models like that of GARCH, EGARCH, GJR, and TARCH along with MRS-GARCH on the S\&P stock market. Study of Fleming, Ostdiek and Whaley (1995) is found using S\&P 100 index and applied regression analysis to find a temporary relationship between the volatility index and stock market returns. They concluded that the CBOE market volatility index can be recommended as a new measure of stock market volatility as it considers market expectation. While Schwert (1990) considered stock market volatility from the investors, regulators, brokers, dealers, and the press perspectives by using standard deviation on the monthly data from New York Stock exchange. The study concluded stating stock volatility increases during the recession and that high volatility is associated with high levels of trading. Additionally, Edwards (1988) assessed the impact on stock price volatility of stock index futures trading from 1972 to 1982 and 1982 to 1986 sample period. Volatility was found lower until 1986 and started rising from 1986 which is not correlated to futures trading and hence concluded that it may be because of fall in the dollar in comparison to other leading currency exchanges or economic deficiencies like that of trade. Hamilton and Lin (1996) work on the stock returns and growth in industrial production indicated that stock returns are 
associated with a longer period of high volatility whereas the mean in industrial production is related to the economic changes. They concluded that an economic change in particular recession influences 60 percent of the stock return variance. Bollerslev and Mikkelsen (1999) study on the stock market volatility have used GARCH models and concluded that the more volatile the underlying asset, the more valuable the same asset will be. Day and Lewis (1992) also used GARCH family models on the S\&P 100index to find information content of the implied volatility on the call option. They concluded having incremental information which was found creating volatility on the call option. Ammann, Skovmand and Verhofen (2009) found evidence of stocks including high beta and small, low-market-to-book ratio and nonmomentum trading at higher implied volatilities when historical volatility is monitored.

\section{Research Gap}

While going through the existing literature on the informational transition, spillover effect and persistence of the index's past volatility leading to the variances in the current stock price, the researcher found a close tie of this work with Koulakiotis, Babalos and Papasyriopoulos (2015) and Floros (2007) that examined stock volatility through Largecap, Midcap and Smallcap index price movements on Greece Stock; Beaupin, Giot and Petitjean (2010) on NYSE stocks, and Ozenbas, Deniz, Pagano, S., Michael, and Schwartz, A., (2010) on Nasdaq, NYSE and FTSE. There are very few existing studies which have considered all the selected indices of this study and also the parameter and test applied in the majority of them are different. Additionally, the sample country and market are also different in the documented studies at least in most of them. Moreover, a study by Khanra and Dhir (2017) and Hiremath and Kamaiah (2010) can be found on the same study parameter and country sample, but their study has limitation which is bridged in this study. The reason being the study on NSE by Khanra and Dhir (2017) was made in comparison of each index (Largecap, Midcap and Smallcap) to the overall stock market index. Their research approach is found hindering the understanding of the individual stock index characteristics and such comparison cannot be made due to the individual stock index contribution to the overall stock market index as Smallcap is contributing only 2 percent and Midcap at 12.9 percent while Largecap represents 76.8 percent. Angelidis and Tessaromatic (2005) also supported this research claim by stating the importance of considering Small stocks to predict its premium and risk which is not related to the overall stock market index. Whereas Hiremath and Kamaiah (2010) study on NSE and BSE has not employed rigorous data analysis hence their study is constraint by the empirical test used. Therefore, the author has felt the need of this study and used rigorous tests in selecting the best model fit on Largecap, Midcap and Smallcap return indices. Goldwhite (2009) also stated not to underestimate the risk and suggested future research to use extensive empirical tools to understand the portfolio behavior. Hence the researcher has tried to contribute to the existing literature by selecting the most recent data as possible depending on data availability and chosen the best model fit after testing for robustness of each test which is explained in the succeeding section of the paper.

\section{RESEARCH METHODOLOGY}

The data under this study is referred from the National Stock Exchange (NSE) Nifty 500 index databases. The period of the study conducted was from April 2007 to March 2020 and from April 2010 to March 2020. The analysis was carried on two sample periods in order to understand if the whole sample period (April 2007 to March 2020) the result is different from its sub-sample period (April 2010 to March 2020). The sub-sample study was undertaken to reduce the variance in the index returns resulting from the financial crisis and recession that followed from the year 2007 to 2009 period which may be causing the index return variance. The monthly data is used for this study to reduce the bias as the information is assumed to be well contained in the data. The Largecap Nifty 100, NIFTY Midcap 150 and NIFTY Smallcap 50are used from the broad market index along with NVIX (Nifty Volatility Index), all of which are explained in Section I. The Univariate test was carried on the three broad market indices for both the sample period and a bivariate test was analyzed by taking NVIX as an exogenous variable on the Largecap stock returns in the sub-sample period in order to understand if variance in the Largecap stock return was 
influenced by the overall market volatility due to its high composition on the overall market index. The index data is recommended instead of using the individual stock data to avoid problems associated with bid-ask bounces or cross-sectional dependencies (Theobald and Yullup, 2005). Therefore, an appropriate data is selected (Angelidis and Tessaromatis, 2005), changed them into a return series and transformed into a log form to eliminate the possible dependence of changes in the stock price index on the price level of the index as well as it yields continuously compounded series (Onyeaso and Rogers,2004). The test model was selected based on the Akaike and Schwarz info criterion (Theobald and Yallup; 2005, Bollerslev and Mikkelsen; 1999, Marcucci; 2005). In addition to that, models are further employed with diagnostic tests so that the results from the analysis will be an objective and reliable. Therefore, the outcome from the analysis can be referred for implications while making an investment decision by investors or economic agents.

The asset return at time $t$ is calculated from the stock price as:

$$
\mathrm{R}_{\mathrm{t}}=\frac{P_{t}-P_{t-1}}{P_{t-1}}
$$

where $\mathrm{R}_{\mathrm{t}}$ is one period spot returns (current) which was converted into log form as:

$$
\mathrm{R}_{\mathrm{t}}=\log \frac{P_{t}-P_{t-1}}{P_{t-1}}
$$

The main test equations are:

$\mathrm{ARCH}(\mathrm{q})$ process:

$y_{t}=\beta_{1}+\beta_{2} x_{2 t}+\beta_{3} x_{3 t}+u_{t} \quad u_{t} \sim \mathrm{N}\left(0, \mathrm{~h}_{\mathrm{t}}\right) \ldots$

$\mathrm{h}_{\mathrm{t}}=a_{0}+a_{1} u_{t-1}^{2}+a_{2} u_{t-2}^{2}+a_{q} u_{t-q}^{2} \cdots$

For the model to have a positive conditional variance, the parameters must be having $a_{0} \geq 0$ and $a_{1}, \ldots, a_{q} \geq 0$. The (1a) describes how the study variable, $y_{t}$, varies over time and the (1b) describes only one lagged squared error. The number of lags was chosen by using optimal lag length selection.

\section{GARCH (p,q) Process}

The GARCH model which is the higher-order AR process was developed by Bollerslev (1986) and Taylor (1986) is a Generalized AutoRegressive Conditional Heteroskedasticity (GARCH) process are:

$\widehat{L} s_{\mathrm{t}}=\mathrm{c}+\mathrm{a} \hat{L} s_{\mathrm{t}-1 \ldots}$

$h_{t}=\phi+\Theta_{1} h_{\mathrm{t}-1}+n_{1} u_{\mathrm{t}-1}^{2}$

where $\mathrm{c}$ is the average stock price index; $\hat{L} s_{\mathrm{t}-1}$ is the past value of the stock price or indices. Equation (2a) is the conditional mean equation and $(2 b)$ is the conditional variance equation which is the linear function of q lags of the squared the error terms $\left(h_{t-1}\right)$ or the ARCH terms ("news") and p lags of its past values of the conditional variances $\left(h_{t}\right)$, and $\Phi$ isa constant term.

\section{Threshold GARCH (TGARCH) Model}

It was proposed by Glosten, Jagannathan, and Runkle in 1993 and Zakoian, 1994.

$h_{\mathrm{t}}=\phi+\Theta_{1} h_{\mathrm{t}-1}+n_{\mathrm{t}} \mathrm{u}_{\mathrm{t}-1}^{2}+\lambda_{1} \mathrm{u}_{\mathrm{t}-1}^{2} \mathrm{D}_{\mathrm{t}-1 \ldots}$ 
where $D_{t}$ takes the value of 1 (bad news) for $\mathrm{u}_{t}<0$, and 0 otherwise. Good news will have an impact on $B_{1}$, while bad news will have an impact on $b_{1}+\lambda_{1}$.

$\lambda$ is an asymmetry or leverage term. $\lambda>0$ is asymmetry, while $\lambda=0$ is symmetry. If $\lambda$ is significant and positive, negative shocks will have a larger effect on $h_{t}$ than the positive shocks.

\section{EGARCH (Exponential GARCH) (p,q) Model}

Since the GARCH process fails in explaining the leverage effects meaning the impact of good news is different from the bad news on the stock price volatility if volatility is detected, therefore EGARCH is adopted. The asymmetry in a time series data is captured in the EGARCH model proposed by Nelson in 1991. This model is similar to the TGARCH model except it uses the log of the variance series.

$\log \left(\mathrm{h}_{\mathrm{t}}\right)=\varphi+\sum_{i=1}^{q} n_{i}\left|\frac{u_{t-i}}{\sqrt{h_{t-i}}}\right|+\sum_{i=1}^{q} \lambda_{i} \frac{u_{t-i}}{\sqrt{h_{t-i}}}+\sum_{k=1}^{p} \theta_{k} \log \left(\mathrm{h}_{\mathrm{t}-\mathrm{k}}\right) \ldots$

where LHS is the log of variance series $\left(\mathrm{h}_{\mathrm{t}}\right)$ thereby ensuring the estimates are non-negative. $\Phi$ is the constant term, $n$ is the ARCH effects, $\lambda$ is the asymmetric effects and $\theta$ is the GARCH effect. If $\lambda_{1}=$ $\lambda_{2}=\ldots=0$ then the model is symmetric and if not then otherwise. But if $\lambda_{i}<0$ or negative, it implies that bad news or negative shocks are generating larger volatility effect than good news or the positive shocks.

The researcher has used autoregressive Conditional Heteroskedasticity (ARCH) model of Engle (1982), GARCH (p,q) model of Bollerslev (1986) and the Exponential GARCH, or EGARCH(p, q) model by Nelson (1991) along with the Threshold GARCH proposed by Glosten, Jagannathan and Runkle (1993) to test for best model fit. The empirical test applied under this study is similar to the work of Shenbagaraman (2003), Marcucci (2005) and Floros(2007). Kalev, et al. (2004) and Bomfim (2003) also suggested using GARCH models to approximate historical volatility and stated that such model is a great improvement over the unconditional volatility measures. Overall, past studies recommended GARCH $(1,1)$ as a standard model for volatility testing (Bollerslev, Chou, and Kroner,1992) and is considered in this study as a benchmark model while simultaneously referring to the different info criterion (Theobald and Yallup, 2005; Bollerslev and Mikkelsen, 1999; Marcucci, 2005). The ht process or conditional variance is referred from the GARCH and EGARCH models therefore selected. The non-linear Gaussian is commonly taken assumptions (Engle and Patton, 2001; Onyeaso and Rogers, 2004) so is used inthis study on the selected models. Hence, GARCH family models are employed on the Univariateand bivariate series analysis to understand the informational changes effect on the stock index return (Engle and Patton, 2001). The advantage of using GARCH family models is its characteristics to detect the volatility clustering and leverage effect and informational transmission to identifythe cause of the changes in the underlying asset prices (Guo and Wohar, 2006; Engle and Patton, 2001)

\section{DATA ANALYSIS}

TABLE 1

DESCRIPTIVE STATISTICS

\begin{tabular}{|c|c|c|c|c|c|l|}
\hline \multirow{2}{*}{ Variables } & \multicolumn{3}{|c|}{$2007-2019$ series } & \multicolumn{3}{c|}{ 2010-2019 series } \\
\cline { 2 - 7 } & Constant & $\begin{array}{c}\text { Constant \& } \\
\text { intercept }\end{array}$ & None & Constant & $\begin{array}{c}\text { Constant \& } \\
\text { intercept }\end{array}$ & None \\
\hline Largecap & -7.33363 & -7.25333 & -7.31746 & -8.175984 & -8.12458 & -8.02775 \\
\hline Midcap & -9.05743 & -9.00888 & -9.08313 & -8.23141 & -8.15964 & -8.24984 \\
\hline Smallcap & -10.5222 & -10.5442 & -10.5596 & -9.0326 & -9.15287 & -9.07355 \\
\hline IndianVIX & - & - & - & -7.471453 & -7.515539 & -7.519372 \\
\hline
\end{tabular}

Note: The table reports the ADF test statistics at First difference; Constant, Constant \& Intercept and None. Lag 3 (2007-2019 Series) and Lag 2(2010-2019 Series) has been used based on the optimal lag length selection suggested by LR, FPE \& AIC. The critical values for the model constant at $1 \%, 5 \%, \& 10 \%$ are $-3.4731,-2.88021$ and -2.57681 ; 
Constant and Intercept model critical value at $1 \%, 5 \%$, and $10 \%$ are $-4.01875,-3.43927$ and -3.144 while None model critical value at $1 \%, 5 \%$ and $10 \%$ are $-2.58007,-1.94291$, and -1.61533 .

Source: Author's own

The test statistics under Table 1 shows evidence of stationarity at constant, constant and intercept and none as it is greater than the critical values at $1 \%, 5 \%$ and $10 \%$ at First difference. Hence, null hypothesis can be rejected stating the model does not have unit root problem and are stationary.

TABLE 2

JARQUE-BERA TEST

\begin{tabular}{|l|l|}
\hline Series & Probability \\
\hline Group (All market capitalization) & 0.21 \\
\hline Largecap \& Nifty VIX & 0.11 \\
\hline
\end{tabular}

Source: Author's own

Under Table 2, the series are showing signs of normal distribution as the probability value is more than 5 percent and hence the null hypothesis of the residuals are normally distributed is accepted.

TABLE 3

ARCH-LM TEST

\begin{tabular}{|l|l|l|}
\hline \multirow{2}{*}{ Variables } & 2007-2019 series & 2010-2019 series \\
\cline { 2 - 3 } & P-values & P-values \\
\hline Largecap & 0.2924 & 0.5788 \\
\hline Midcap & 0.8950 & .9884 \\
\hline Smallcap & 0.8625 & 0.4545 \\
\hline LargecapIndiaVIX & & .3246 \\
\hline
\end{tabular}

Source: Author's own

The ARCH LM test under Table 3 is showing p-values more than 5 percent. Therefore, null hypothesis stating there is no ARCH effect in the residuals is accepted on all the series.

TABLE 4

VOLATILITY ESTIMATE: ALL SERIES

\begin{tabular}{|c|c|c|c|c|}
\hline Panel A: & \multicolumn{2}{|c|}{ 2007-2019 Series } & \multicolumn{2}{|c|}{ 2010-2019 Series } \\
\hline $\begin{array}{l}\text { Largecap series } \\
\text { EGARCH }(1,1)\end{array}$ & Gaussian & P-value & Gaussian & P-value \\
\hline$\Phi$ & 7.131 & 0.00 & 1.383 & 0.00 \\
\hline$N$ & 1.028 & 0.00 & 0.616 & 0.00 \\
\hline$\Lambda$ & -0.332 & 0.00 & 0.205 & 0.00 \\
\hline$\theta$ & -0.064 & 0.45 & 0.717 & 0.00 \\
\hline AIC & \multicolumn{2}{|c|}{-3.092} & \multicolumn{2}{|c|}{-3.653} \\
\hline $\mathrm{SCH}$ & \multicolumn{2}{|c|}{-2.975} & \multicolumn{2}{|c|}{-3.513} \\
\hline $\begin{array}{l}\text { Midcap Series TARCH } \\
(1,1)\end{array}$ & Gaussian & P-value & Gaussian & P-value \\
\hline$\Phi$ & 0.456 & .29 & 10.318 & 0.00 \\
\hline$N$ & 0.145 & .245 & 0.253 & 0.17 \\
\hline
\end{tabular}




\begin{tabular}{|l|c|c|c|c|}
\hline$\Lambda$ & -0.113 & 0.04 & 0.108 & 0.41 \\
\hline$\Theta$ & 0.933 & 0.00 & 0.841 & 0.00 \\
\hline AIC & \multicolumn{2}{|c|}{-2.374} & \multicolumn{2}{c|}{-2.755} \\
\hline SIC & \multicolumn{2}{|c|}{-2.256} & Gaussian & P-value \\
\hline $\begin{array}{l}\text { Smallcap Series } \\
\text { GARCH(1,1) }\end{array}$ & Gaussian & P-value & 0.0002 & 0.00 \\
\hline$\Phi$ & 0.005 & 0.00 & 0.094 & 0.00 \\
\hline$N$ & 0.124 & 0.38 & 1.062 & 0.00 \\
\hline$\Theta$ & 0.501 & 0.00 & \multicolumn{2}{c|}{-2.499} \\
\hline AIC & \multicolumn{2}{|c|}{-2.105} & & -2.382 \\
\hline SIC & \multicolumn{2}{|c|}{-2.007} \\
\hline
\end{tabular}

Source: Author's own

Under the Table 4, Largecap series for both the sample period are significant with p-value lesser than 5 percent level meaning, the previous day's return information can influence today's return volatility as well as negative shock or bad news has larger effect on today's return volatility. It is also found that GARCH term is not significant under 2007-2019 Sample series meaning previous day's return volatility cannot influence today's return volatility and that there is no volatility persistence or long memory in the index return volatility characteristics.

Whereas for Midcap, the test result is suggesting that there is no $\mathrm{ARCH}$ and asymmetry effect as its value is not significant yet GARCH effect can be seen meaning there is persistence of volatility in the series or variances which is caused by external factors and not by its own shock. For Smallcap also it can be seen that there is persistence of volatility as well as spillovers effect as both the ARCH and GARCH terms are found having significant p-value. Such reaction is caused by its own previous day's return volatility, news on its return and spillovers effect.

Largecap and VIX: EGARCH $(1,1)$

$\log \left(\mathrm{h}_{\mathrm{t}}\right)=\varphi^{+} \sum_{i=1}^{q} n_{i}\left|\frac{u_{t-i}}{\sqrt{h_{t-i}}}\right|+\sum_{i=1}^{q} \lambda_{i} \frac{u_{t-i}}{\sqrt{h_{t-i}}}+\sum_{k=1}^{p} \theta_{k} \log \left(\mathrm{h}_{\mathrm{t}-\mathrm{k}}\right)+\mathrm{NVIX} \mathrm{t}_{\mathrm{t}-1} \ldots$

On the equation (4), VIX is added as an exogenous variable on the Largecap stock index returns in order to find out if the overall market volatility is affecting the Largecap series.

TABLE 5

VOLATILITY ESTIMATES: LARGECAP AND VIX

\begin{tabular}{|l|l|l|}
\hline \multirow{2}{*}{ EGARCH $(1,1)$} & $2010-2019$ Series \\
\cline { 2 - 3 } & Gaussian & P-value \\
\hline$\Phi$ & -26.2773 & 0.00 \\
\hline$n$ & 0.68284 & 0.01 \\
\hline$\Lambda$ & 0.16109 & 0.16 \\
\hline$\Theta$ & -0.77489 & 0.00 \\
\hline VIX & 4.6368 & 0.00 \\
\hline AIC & \multicolumn{2}{|c|}{-4.11422} \\
\hline SCH & \multicolumn{2}{|c|}{-3.95074} \\
\hline
\end{tabular}

Source: Author's own

From the Table 5, the test result is showing evidence of the ARCH, GARCH and NVIX effect. The volatility in the Largecap is dependent on the variance in the previous day's return information which is influencing today's return volatility which is purely showing signs of spillover effects. The persistence in 
volatility can be found through past volatility predicting the future volatility in addition to exogenous variables effect on the Largecap series as their p-values are significant. Yet it is found that there is no leverage or asymmetric effect as the p-value of the asymmetry term is not significant.

The models selected were tested with diagnostic tests in the residuals (Ljung-Box, Jarque-Bera, and LM test).Almost all the series are having existence of mean reversion $(n+\Theta)$. It means when the underlying asset price reaches high, it is likely to decrease and over time it will move around the assets mean or average value which is not constant (Guo and Wohar, 2006). Such underlying asset volatility behavior can be due to the meteor shower effect or heatwave (Engle and Patton, 2001) effect.

\section{CONCLUSIONS}

This study was conducted to answer the research gaps on all the three market indices in terms of assessing the different endogenous effects through a rigorous testing. It can be concluded that there is an existence of time-varying volatility through informational transition in the indices, spillovers and leverage effect. The result of variances in the Index return is found due to the informational transition in time-varying phases when there are changes in the economic indicator which is shown from the evidence of the ARCH effect on the indices. The reason of seeing the information transition in the series may be due to the investor sentiment (Liston and Huerta, 2012; Schmeling, 2009) as Indian society is influenced by opinion of one's family including extended family members, and affiliations either from a workplace or social networks (Hofstede Insights Individualism index, 2010). Or it might be due to the importance given to the individual investors and advancement of technology which helped in accessing inexpensive trading opportunities (Ankrim and Ding, 2002). Additionally, finding persistence of volatility in all the selected series is good from many aspects but only if it is due to the informational transfusion (Theobald and Yallup, 2005) and are traded based on the economic activity rather than influenced by others or sentiment bias.

\section{RECOMMENDATIONS}

Goldwhite (2009) concluded that investors should be cautious and informed to understand stock volatility. Hence, following are the recommendations to be agile in the constantly changing information. First, to the investors or potential investors; who has expectations from their investments due to the evidence of the persistence in the index volatility as the future benefits of the cash inflows will have a discounting effect and therefore it is recommended to invest at the right time depending on individual risk tolerance tradeoff to the expected reward. The investors can therefore use similar rigorous tests analyzed in this work to understand the behavior of a portfolio before investing. Huberman and Regev (2001) Andrei and Hasler (2014) claimed that the stock price changes only when the investors are paying attention to the information flow. For policymakers; these indices can be considered to monitor how the economy is performing at the fractional market level and the tools applied under this study can be considered to understand if its own factor or others are affecting the index behavior and the reason behind the asymmetry. For traders, market makers or economic agents, it can be suggested that such methods of finding variance in the index returns in a time series data can be used in building an optimal portfolio which will help to formulate proper financial strategy and also help in building a portfolio appropriate to individual risk preference, allocation of the asset can be conveniently done along with minimizing risk and pricing for the same (Blasco, Corredor and Ferrerela, 2012).

\section{FUTURE SCOPE OF STUDY}

The author suggests for consideration of the different broad market indices from BSE along with NSE in order to be able to provide a better understanding of the Indian stock index return behavior. Finding a unanimous study result will enhance the reliability of taking an investment decision or preference of investments in the Indian stock index. 


\section{ACKNOWLEDGEMENT}

The author wants to acknowledge the research guidance received from Prof. Badrinath, an FPM and alumni from IIMB (Indian Institute of Management, Bangalore). Sir has almost two decades in experience working in both corporate as well as in academics in the field of Finance.

\section{REFERENCES}

Ali, G. (2013). EGARCH, GJR-GARCH, TGARCH, AVGARCH, NGARCH, IGARCH and APARCH models for Pathogens at Marine recreational sites. Journal of Statistical and Econometric Methods, 2(3), 57-73.

Ammann, M., Skovmand, D., \& Verhofen, M. (2009). Implied and Realized Volatility in the crosssection of equity options. International Journal of Theoretical and Applied Finance, 12(6), 745765. doi.org/10.2139/ssrn. 1324605

Andrei, D., \& Hasler, M. (2014). Investor attention and stock market volatility. The Review of Financial Studies, 28(1). doi.org/10.1093/rfs/hhu059

Angelidis, T., \& Tessaromatis, N. (2005). Equity Returns and Idiosyncratic Volatility: UK Evidence. SSRN Electronic Journal. doi:10.2139/ssrn.733906

Ankrim, M.E., \& Ding, Z. (2002, September/October). Cross-sectional volatility and return dispersion. Financial Analysts Journal, pp. 67-73.

Barinov, A. (2012). Aggregate volatility risk: Explaining the small growth anomaly and the new issues puzzle. Journal of Corporate Finance, 18(4), 763-781. doi.org/10.2139/ssrn.1030479

Beaupain, R., Giot, P., \& Petitjean, M. (2010). Liquidity co-movements, market capitalization, and volatility. Journal of the French Finance Association, 31(1).

Blasco, N., Corredor, P., \& Ferreruela, S. (2012, February). Does herding affect volatility? Implications for the Spanish stock market. Quantitative Finance, 12(2).

Bollerslev, T., \& Mikkelsen, O.H. (1999). Long-term equity anticipation securities and stock market volatility dynamics. Journal of Econometrics, 92(1), 75-99.

Bollerslev, T., Chou, R., \& Kroner, F.K. (1992). ARCH modeling in finance: A review of the theory and empirical evidence. Journal of Econometrics, 52(1-2), 5-59.

Bomfim, A.N. (2003). Pre-announcement effects, news effects, and volatility: Monetary policy and the stock market. Journal of Banking and Finance, 27, 133-151.

Conrad, C., \& Weber, E. (2013, April 15). Measuring Persistence in Volatility Spillovers. University of Heidelberg, Department of Economics, Discussion Paper No. 543. doi.org/10.2139/ssrn.2251141

Copeland, M.M., \& Copeland, T.E. (1999). Market Timing: Style and Size Rotation Using the VIX. Financial Analysts Journal, 55(2), 73-81. doi:10.2469/faj.v55.n2.2262

Cotter, J., \& Simon, S. (2007). Uncovering Volatility Dynamics in Daily REIT Return. Journal of Real Estate Portfolio Management, 13(2), 119-128.

Day, E.T., \& Lewis, M.C. (1992). Stock market volatility and the information content of stock index options. Journal of econometrics, 52, 267-287. North-Holland.

Edwards, F.R. (1998, January-February). Does futures trading increase stock market volatility? Financial Analysts Journal, pp. 63-69.

Engle, R.F., \& Patton, A.J. (2001). What good is a volatility model? Quantitative Finance, 1(2), 237-245. doi.org/10.1016/B978-075066942-9.50004-2

Engle, R.F., Ghysels, E., \& Sohn, B. (2013, July). Stock market volatility and macroeconomic fundamentals. The Review of Economics and Statistics, 95(3), 776-797.

Eun, C.S., Huang, W., \& Lai, S. (2008). International Diversification with Large- and Small-Cap Stocks. Journal of Financial and Quantitative Analysis, 43(02), 489-524.

Fleming, J., Ostdiek, B., \& Whaley, E.R. (1995). Predicting stock market volatility: A new measure. The Journal of Futures Markets, 15(3), 265-302.

50 Journal of Applied Business and Economics Vol. 22(14) 2020 
Floros, C. (2007). The effects of international accounting standards on stock market volatility: The case of Greece. Investment Management and Financial Innovations, 4(1), 61-72.

Giliberto, S.M. (2003). Assessing Real Estate Volatility. The Journal of Portfolio Management, 29(5), 122-128. doi:10.3905/jpm.2003.319913

Goldwhite, P. (2009). Diversification and Risk Management: What Volatility Tells Us. The Journal of Investing, 18(3), 40-48. doi:10.3905/joi.2009.18.3.040

Guo, W., \& Wohar, M.E. (2006, Spring). Identifying Regime changes in market volatility. Journal of Financial Research, 29(1), 79-93.

Hamilton, D.J., \& Lin, G. (1996). Stock market volatility and the business cycle. Journal of Applied Econometrics, 11, 573-593.

Hiremath, G.S., \& Kamaiah, B. (2010, December). Long Memory in Stock Market Volatility: Indian Evidences. ArthaVijnana, 52(4), 332-345.

Hofstede, G., Hofstede, G.J., \&Minkov, M. (2010). Cultures and organizations: Software of the mind, Revised and Expanded (3rd Edition). New York: McGraw-Hill.

Huberman, G., \& Tomer, R. (2001). Contagious speculation and a cure for cancer. A nonevent that made stock prices soar. Journal of Finance, 56(1), 387-396.

Kalev, P., Liu, W., Pham, P.K., \& Jarnecic, E. (2004). Public information arrival and volatility of intraday stock returns. Journal of Banking and Finance, 28, 1441-1467.

Khanra, S., \& Dhir, S. (2017). Creating Value in Small-cap firms by mitigating risks of market volatility. SAGE Publications, 2l(4), 350-355. DOI: 10.1177/0972262917733166

Koulakiotis, A., Babalos, V., \& Papasyriopoulos, N. (2015). Liquidity matters after all: Asymmetric news and stock market volatility before and after the global financial crisis. Economics Letters, 127, 58-60.

Kuo, L-L., \& Li, F. (2013). An Investor's Low Volatility Strategy. The Journal of Index Investing, 3(4), 8-22. doi:10.3905/jii.2013.3.4.008

Lee, Y.W., Jiang, X.C., \& Indro, C.D. (2002). Stock market volatility, excess returns, and the role of investor sentiment. Journal of Banking and Finance, 26(12), 2277-2299.

Lizhong, C., \& Meng, Z. (2013). Open-end Funds feedback trading behavior: Existence test and the impact on stock price volatility. Journal of Finance and Economics, pp. 94-107.

Marcucci, J. (2005). Forecasting stock market volatility with regime-switching GARCH models. University of California, 9(4), 1-53.

McMillan, D., Speight, A., \& Apgwilym, O. (2000). Forecasting U.K. stock market volatility. Applied Financial Economics, 10(4), 435-448. Retrieved June 15, 2020, from www.tandfonline.com/action/showCitFormats?doi=10.1080/09603100050031561

Mele, A. (2007). Asymmetric stock market volatility and the cyclical behavior of expected returns. Journal of Financial Economics, 86(2), 446-478.

Onyeaso, G., \& Rogers, M. (2004). An Econometric Investigation of the Volatility and Market Efficiency of the U. S. Small Cap 600 Stock Index. Quarterly Journal of Business and Economics, 43(3/4), 139-155.

Ozenbas, D., Pagano, M.S., \& Schwartz, R.A. (2010). Accentuated Intraday Stock Price Volatility: What is the Cause? The Journal of Portfolio Management, 36(3), 45-55.

Perez-Liston, D., \& Huerta, D. (2012). Does investor sentiment affect Mexican stock market returns and volatility? The Global Journal of Finance and Economics, 9(2), 121-132.

Perez-Liston, D., Huerta, D., \& Haq, S. (2014). Does investor sentiment impact the returns and volatility of Islamic equities? Journal of Economics and Finance, 40(3). DOI 10.1007/s12197-014-9290-6

Reyes, M.G. (2001). Asymmetric volatility spillover in the Tokyo stock exchange. Journal of Economics and Finance, 25(2), 206-213. doi:10.1007/bf02744523

Schmeling, M. (2009). Investor sentiment and stock returns: Some international evidence. Journal of Empirical Finance, 16, 394-408.

Schwert, W.G. (1989, December). Why does stock market volatility change over time? The Journal of Finance, $X L I V(5)$. 
Schwert, W.G. (1990, May-June). Stock market volatility. Financial Analysts Journal, pp. 23-34.

Shenbagaraman, P. (2003). Do Futures and Options trading increase stock market volatility. Economics. Semantic Scholar.

Theobald, M., \& Yallup, P. (2005). Intradaily volatility and adjustment. Journal of International Financial Markets, Institutions and Money, 15(5), 407-424.

Van Zundert, J. (2017). A New Test for Cross-Sectional Momentum. SSRN Electronic Journal. Retrieved June 15, 2020: doi:10.2139/ssrn.2880097

Wei, S.Y., \& Yang, J.J.W. (2011, June). The Impact of Short Sale Restrictions on Stock Volatility: Evidence from Taiwan. International Journal of Business and Finance Research, 5(4), 89-98. doi.org/10.2139/ssrn. 1571601 